\title{
Microalbuminuria as a Predictor of Short-Term Mortality in Acute Ischemic Stroke
}

\author{
J Chowdhury1 ${ }^{1}$ N Sultana², S Ahmed 3 , MM Rahman', M Akter5, T Rafique6 \\ ${ }^{1}$ Dept of Biochemistry, MH Samorita Medical College, Panthapath, Dhaka \\ 2Dept of Biochemistry, Dhaka Medical College Dhaka \\ ${ }^{3}$ Dept of Biochemistry, Popular Medical College, Dhaka \\ ${ }^{4}$ Dept of Biochemistry, Dhaka National Medical College Dhaka \\ ${ }^{5}$ Dept of Biochemistry, Khawaja Yunus Ali Medical College, Sirajgonj \\ ${ }^{6}$ Dept of Biochemistry, Sapporo Dental Medical College, Dhaka
}

\begin{abstract}
Stroke is one of the major causes of morbidity and mortality all over the world. Microalbuminuria is one of the predictors of mortality. Available published data has suggested that microalbuminuria is a potential new risk factor for ischemic stroke. This study was carried out in the Department of Biochemistry, Dhaka Medical College during the period from July 2009 to June 2010. In this study, we enrolled 120 patients of ischemic stroke. 60 of them were with microalbuminuria (MA) and 60 were without MA. Among the MA + ve group, $38(63.3 \%)$ were males and $22(36.7 \%)$ were females. On the other hand those belonging to MA -ve groups $52(36.7 \%)$ were males and $8(13.3 \%)$ were females. Age range of the subjects in MA + ve group was 45-70 years and in MA-ve group was 50-70 years. In patients with microalbuminuria mortality was $26.7 \%$ and in patients without MA mortality was $11.7 \%(\mathrm{p}<0.05)$. The study showed significantly higher mortality in patients with microalbuminuria than that of the patients without microalbuminuria.
\end{abstract}

Key Word: Microalbuminuria, short-term mortality, Acute ischemic stroke

\section{Introduction}

Stroke is a focal neurological deficit due to vascular lesion. It is the third most common cause of death in developed countries. The age adjusted annual death rate from stroke is 116 per 100000 population in USA and 200 per 100000 populations in UK. It is higher in Afro-Caribian population than Caucasians. Stroke is uncommon below the age of 40 yers and is more in males. ${ }^{1}$

Stroke is classified into two main types Ischemic stroke and Hemorrhagic stroke. Ischemic stroke accounts for about $83 \%$ of all cases and it occurs as a result of an obstruction within a blood vessel. Obstruction may be either by thrombus around atherosclerotic plaque or by embolism. ${ }^{2}$

Risk factors or risk markers for stroke are classified according to their potential for modification. Modifiable risk factors are Bangladesh J Med Biochem 2012; 5(1): 16-19 hypertension, exposure to cigarette smoke, DM, atrial fibrillation and certain other cardiac conditions. 3

For ischemic stroke there are some potential new risk factors which include some genotypes, inflammatory markers and functional markers like Microalbuminuria 4 . Normally urinary albumin excretion is less than $20 \mathrm{mg} /$ day. Microalbuminuria is defined as abnormal urinary excretion of albumin between 30 and $300 \mathrm{mg} /$ day. In a recent report an overnight urinary albumin excretion (UAE) above only $5 \mu \mathrm{gm} / \mathrm{min}$ was strongly predictive of coronary heart disease and death in general population. It may reflect generalized vascular damage that means endothelial dysfunction (ED) and ED is an early marker of atherosclerosis. 5,6 It also reflects glomerular component of systemic capillary leak which is 
fundamental to the pathogenesis of any acute stress condition. ${ }^{7}$

There is a close relation between atherosclerosis, endothelial dysfunction (ED) and leakage of protein through glomerulus. ED can be considered when endothelial properties have changed in a way that is inappropriate with regard to the preservation of organ function. In ED most potent endogenous vasodilator, Nitric oxide production or its activity, is hampered which leads to arterial vasoconstriction. This causes increase arterial as well as glomerular pressure and permeability. In ED, glomerular basement membrane losses its normal negative charges 8 .

ED also causes loss of surface heparin like proteoglycan molecules that prevent thrombus formation and smooth muscle growth thus promoting thrombus formation and intimal thickening which enhance atherosclerosis. So in ED both MA and atherosclerosis are found. Most of the acute ischemic stroke happened due to atherosclerosis by sudden occlusion of the lumen developed by the superimposed thrombosis or hemorrhage into atheroma 9 .

Microalbuminuria and atherosclerosis found in ED is manifested as increased intima-media thickness of common carotid arteries 10 .

Measurement of urinary microalbumin may be one of the most important screening tests for determining the risk of atherosclerotic disease as well as those who are prone to develop ischemic stroke. In Bangladesh no definite data regarding microalbuminuria which predicts mortality that occurs within 14 days of the attack in acute ischemic stroke available. Therefore the present study is designed to explore the correlation between microalbuminuria and mortality in acute ischemic stroke patients.

\section{Materials \& Methods}

A cross sectional study was carried out in the Department of Biochemistry, Dhaka Medical College, Dhaka with active cooperation of the
Department of Neurology, DMCH from July 2009 to June 2010. A total of 120 hospitalized patients with acute ischemic stroke were selected as study subjects. 60 patients of acute ischemic stroke with microalbuminuria and 60 patients of acute ischemic stroke without microalbuminuria were selected. Patients with DM, Renal disease, Liver disease, heart failure, acute febrile illness, infection of urinary tract were excluded from the study.

Laboratory analysis was done with fasting venous blood and urine. Spot urine was collected in eppendorf and was stored at $-35^{\circ} \mathrm{c}$ until analytical measurements done. Microalbuminuria was estimated by immunometric method.

With all aseptic precautions $5 \mathrm{ml}$ fasting venous blood was collected by disposable plastic syringe. Blood was transferred immediately into clean test tube. Collected blood was allowed to clot and centrifuged at $3000 \mathrm{rpm}$. Separated serum was collected in eppendorf tube and labeled properly for estimation of fasting blood sugar, lipid profile and serum creatinine.

Statistical analysis was performed by using computer based software SPSS version 17.0. The data were expressed as the Mean \pm SD. Unpaired Student's ' $t$ ' test, Chi-square test, Logistic Regression analysis was used to see the level of significance. $95 \%$ confidence limit $(p<0.05)$ was taken as level of significance.

\section{Results}

Table-I shows the age distribution of the study subjects in terms of assigned age groups. It was found that $4(6.7 \%) \mathrm{MA}$ +ve and no MA -ve group belonged to the age group of $<50$ years. In age group 50-59 years $8(13.3 \%)$ were $\mathrm{MA}+\mathrm{ve}$ and $22(36.7 \%)$ were MA-ve. In $\geq 60$ years age group $48(80 \%)$ were $\mathrm{MA}+\mathrm{ve}$ and 38 $(63 \%)$ were MA -ve. 
Microalbuminuria as a Predictor of Short Term Mortality in Acute

Table-I: Distribution of the study subjects by age

\begin{tabular}{ccccccc}
\hline Age (years) & \multicolumn{2}{c}{ MA +ve } & \multicolumn{2}{c}{ MA -ve } & $\chi^{2}$ value & P value \\
& Frequency & Percent & Frequency & Percent & & \\
\hline$<50$ & 4 & 6.7 & 0 & 0 & & \\
50.59 & 8 & 13.3 & 22 & 36.7 & 5.848 & $>0.05$ \\
$\geq 60$ & 48 & 80.0 & 38 & 63.3 & & \\
Mean \pm SD & $62.96 \pm 7.94$ & $60.97 \pm 6.03$ & \\
Range & $45.00 \pm 70.00$ & $50.00 \pm 70.00$ & \\
\hline
\end{tabular}

Chi-square test was done to test level of significance

Distribution of the MA+ve \& MA-ve according to sex was shown in Table II. In this study among the MA+ve group, 38 (i.e 63.3\%) were males while $22(36.7 \%)$ were females. On the other hand those belonging to MA-ve group, 52 $(86.7 \%)$ were males and $8(13.3 \%)$ were females. In both group stroke was more common in males.

Table-II: Distribution of the study subjects by sex

\begin{tabular}{|c|c|c|c|c|c|c|}
\hline \multirow{2}{*}{ Sex } & \multicolumn{2}{|c|}{$\mathrm{MA}+\mathrm{ve}$} & \multicolumn{2}{|c|}{ MA -ve } & \multirow{2}{*}{$X^{2}$ value } & \multirow{2}{*}{ P valu } \\
\hline & Frequency & Percent & Frequency & Percent & & \\
\hline Male & 38 & 63.3 & 52 & 86.7 & 4.356 & $<0.05$ \\
\hline Female & 22 & 36.7 & 8 & 13.3 & & \\
\hline
\end{tabular}

Chi-square was done to test level of significance

Table-III: shows association of short term mortality with microalbuminuria among the study subjects. Among MA+ve and MA-ve cases number of patients expired were $73.3 \%$ \& $26.7 \%$ respectively. $\chi 2$ value was 4.357 , p value $<0.05$ and odds ratio was 2.75 which was statistically significant.

Table-III: Association of short term mortality with microalbuminuria among the study subjects

\begin{tabular}{lllllllll}
\hline MA & \multicolumn{1}{c}{ Expired } & Survived & $\chi^{2}$ Value & P Value & OR \\
\hline MA + ve & 44 & $(73.3)$ & 53 & $(88.3)$ & & & \\
& & & & & 4.357 & $<0.05$ & 2.75 \\
MA_ve & $\mathbf{1 6}$ & $\mathbf{( 2 6 . 7 )}$ & 7 & $(\mathbf{1 1 . 7})$ & & & \\
\hline
\end{tabular}

$\chi^{2}$ test was done to test level of significance
Logistic regression of the short term mortality with respect to MA in acute ischemic stroke patient was shown in Table -IV. Here regression coefficient was 2.445 and odds ratio was 11.530. Analysis shows there was a significant relation between mortality and MA.

Table-IV: Logistic regression of the short term mortality with respect to MA in acute ischemic stroke

\begin{tabular}{|c|c|c|c|c|}
\hline Parameter & $\begin{array}{c}\text { Regression } \\
\text { Coefficient } \\
\text { (B) }\end{array}$ & SE & p value & $\begin{array}{c}\text { Odds ratio } \\
{[\operatorname{Exp}(B)]}\end{array}$ \\
\hline \multicolumn{5}{|c|}{$\mathrm{MA}+\mathrm{Ve}$} \\
\hline & 2.445 & 0.539 & 0.10 & 11.530 \\
\hline \multicolumn{5}{|l|}{ MA-Ve } \\
\hline Reference c & ory & 1 & & \\
\hline
\end{tabular}

\section{Discussion}

Stroke has got some risk factors. Various studies have been done throughout the world to study the risk factors of ischemic stroke and also the predictors of mortality of stroke patients. Besides the conventional risk factors, recently MA has been considered as a potential new risk factor for ischemic stroke. It has also been studied as a predictor of mortality.

In the present study, the age of the study population ranged from 45-70 years. In MA+ve groups $86 \%$ and in MA-ve groups $63 \%$ respectively were belonged to the age group of $\geq 60$. In case of distribution of sex in MA+ve groups, males were $63.3 \%$ and female were $36 \%$. Whereas in MA-ve group males were $86.7 \%$ and females were $13.3 \%$.The Differences of mean age and sex between two groups were not found to be statistically significant.

The present study revealed mortality of stroke patients with MA and without MA. In patients with MA mortality was $26.7 \%$ and in patients without MA mortality was $11.7 \%$. Chi-square test and Logistic regression analysis showed the mortality to be significantly higher in patients with MA. This finding is consistent with the study of Ghosh et $a l^{2}$. who conducted a 
prospective study. They studied 89 non-diabetic patients of acute ischemic stroke to investigate the prevalence and significance of MA as a predictor of hospital mortality. Two groups consisted of 70 patients with chronic neurological diseases and 60 age sex matched healthy individuals. Spot urinary albumin creatinine ratio was measured in first morning sample on days 1,4 and/or 7. MA was found in $61.79 \%$ of acute ischemic stroke patients on day 1 compared to $13 \%$ in non stroke neurological patients and $7 \%$ of healthy controls. The 14-day disease specific mortality was higher in patients with MA (25.45\%) compared to patients without it $(5.88 \%)$.

Klausen performed a study that showed a very low level of MA associated with increased risk of death in subjects with cardiovascular diseases. 491 men and women aged 30-80 years with a history of coronary heart diseases delivered a timed overnight urine sample. During follow-up, 141 of the 491 participants died. The death risks associated with MA were univariate Cox proportional hazards regression analysis. The relative risk of death in subjects with urinary albumin excretion (UAE) above $5 \mu \mathrm{gm}$ per minute compared with subjects with lower UAE was 2.0 $(\mathrm{p}<0.001)$. Thus it was concluded that subjects with cardiovascular diseases had about $100 \%$ higher risk of death if MA defined as UAE above $5 \mu \mathrm{gm} / \mathrm{min}$ was present.

All causes mortality was $9.4 \%$ among patients without MA versus $18.2 \%$ among those with MA (Relative risk was 2.09).

The present data showed that short-term mortality of acute ischemic stroke patients having MA compared to patients without MA was higher.
J Chowdhury, N Sultana, S Ahmed et al

\section{References}

1. Clark CRA. Neurological disease. In: Kumar P, Clark M (eds). Kumar and Clark Clinical Medicine. Philadelphia; Saunders, 2002: 1123-24.

2. Ghosh G, Bandyopadhyay SK, Sankar N. Microalbuminuria: A predictor of short-term Mortality in Acute Ischemic Stroke. J Ind Med Assoc 2009; 106: 783-86.

3. Goldstein LB, Adams R, Brass LM, Bushnell CD, Appel LJ, Culebras A et al. Primary prevention of Ischemic Stroke. Stroke 2006; 37: 1583-90.

4. Hankey GJ. Potential New Risk Factors for Ischemic Stroke: What is their potential? Stroke 2006; 37: 2181-88.

5. Klausen KP, Scharling H, Jensen JS. Very low level of microalbuminuria is associated with increased risk of death in subjects with cardiovascular or cerebrovascular diseases. J Intern Med 2006; 260: 231-37.

6. Mykkanen L, Zaccaro DJ, O'Leary DH, Howard G, Robbins DC, Haffner SM. Microalbuminuria and Carotid Artery Intima-Media Thickness in non diabetic and NIDDM Subjects. Stroke 2003; 28: 1710-60.

7. Pontremoli R, Leoncini G, Ravera M, Viazzi F, Vettoretti S, Ratto E, et al Microalbuminuria, Cardiovascular and Renal Risk in Primary Hypertension. J Am Soc Nephrol 2002; 13: 169-72.

8. Schoen FJ. Blood vessels. In: Kumar V, Abbas AK, $\mathrm{N}$ Fausto (eds). Robbins and Cotran PATHOLOGIC BASIS OF DISEASE. Elsevir Saunders, Philadelphia, 2006: 467-516.

9. Skidmore CT, Katzan IL 2002, Stroke, Disease Management Project, viewed 2 February,2010. http://www.clevelandclinicmeded.com/medicalpubs/d iseasemanagement/neurology/stroke/stroke1.htm/.

10. Stehouwer CDA. Endothelial dysfunction in diabetic nephropathy. Nephrol Dial Transplant 2003; 19: 778-81. 